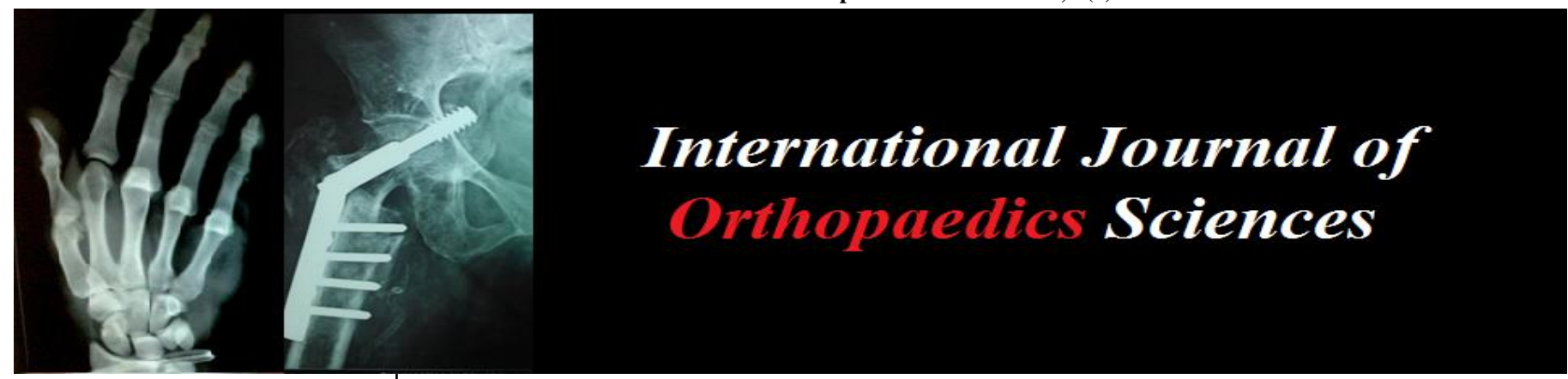

ISSN: $2395-1958$

IJOS 2018; 4(1): 434-438

(C) 2018 IJOS

www.orthopaper.com

Received: 02-11-2017

Accepted: 03-12-2017

Dr. Bhargav Desai

$3^{\text {rd }}$ year resident, Dept of Orthopedics, Gopi vidhyanagar road, Anand, Gujarat, India

Dr. Harsha Makwana Associate Professor, Dept of Emergency Medicine, Opposite Isanpur post office, Isanpur Ahmedabad, Gujarat, India

Dr. Darshan Shah $2^{\text {nd }}$ year resident, Dept of Orthopedics, anand,

Ahmedabad, Gujarat, India

Dr. Pankaj R Patel

Professor, Dept of Orthopedics \&

Dean N.H.L. medical college,

Ahmadabad, Gujarat, India

Correspondence

Dr. Bhargav Desai

$3^{\text {rd }}$ year resident, Dept of

Orthopedics, Gopi vidhyanagar

road, Anand, Gujarat, India

\section{Epidemiology of hand injuries in adults presenting to a tertiary trauma care centre: A descriptive study}

\author{
Dr. Bhargav Desai, Dr. Harsha Makwana, Dr. Darshan Shah and Dr. \\ Pankaj R Patel
}

DOI: https://doi.org/10.22271/ortho.2018.v4.i1g.62

\section{Abstract}

1.1 Introduction: The hand of a Man is his most prized possession, and any injury to it has the potential to produce significant and permanent impairment to hand functions and that in turn can cause mental and financial burden. Hand injuries are very common in present world mainly due to industrialization. Studies conducted show that hand injuries presenting in a tertiary care centre constitute approximately $10 \%$ of all the trauma cases and present from simple lacerations and contusions to crush injuries and amputations; requiring timely and skillful management to improve the prognosis.

1.2 Aim: The aim of this study is to evaluate the epidemiology of hand injuries and understand relation between mechanism of injury and prognosis and to study the Socio-economic impact. This study will provide us with better understanding of the various etiological factors for hand injuries and will help us to develop preventive and therapeutic measures for the same.

1.3 Methods: This study was conducted among 200 patients presenting with hand injuries, in the OPD and CASUALTY of our hospital over a period of two year from January 2015 to December 2016.

1.4 Results: Males $(88 \%)$ are affected more as compared to females $(12 \%)$. The commonest age group affected was $25-35$ years (36\%) followed by $15-25$ years $(28 \%)$. The commonest contributing factor was machine injury $(52.5 \%)$ followed by road traffic accidents $(25 \%)$ and assault $(13.5 \%)$ respectively. The index $(26 \%)$ and middle $(24 \%)$ fingers were involved more commonly.

1.5 Conclusions: Hand injuries are more common in an adult male working in industries who required to operate complex machinery followed by Road Traffic Accidents.

Keywords: Hand injury, epidemiology, machine injury

\section{Introduction}

The Hand is identified throughout history of mankind as an important component of one's anatomy. The human hand is extremely complex and thus difficult to understand. Studies conducted show that hand injuries presenting in a tertiary care centre constitute approximately $10 \%$ of all the trauma cases and present from simple lacerations and contusions to crush injuries and amputation ${ }^{[1]}$. The main reasons of hand injuries include-machine injuries (cutting machines, thresher machines, sugarcane grinders, printing presses etc), Road traffic accidents, sports injuries, assault, glass injuries, fall of heavy object and fall down from height. Their clinical presentation ranges from minor complaints of pain to traumatic amputation of the hand [3]. The physical, mental, financial, as well as social impact of the disability that arise as a sequel to hand injuries is gruesome.

This study will provide us demographic facts and contributing factors regarding hand injuries with better understanding of the various etiological factors, which will help us to develop preventive and therapeutic measures for the same ${ }^{[2]}$.

Aim: To evaluate the epidemiology of isolated hand injuries for demographic data, mode of injury, operative intervention.

\section{Materials and methods}

This observational study was conducted at our Hospital, which is one of the major tertiary trauma care centre run by Municipal Corporation and catered by 108 emergency services. 
In this study we have included 200 patients with Hand injury presenting to OPD and Casualty department of our hospital, from a period of January 2015 to December 2016.

Inclusion criteria: Patients greater than 15 years of age and willing for the study, presented with injury on the hand without any neurovascular impairment of any proximal part were selected.

Exclusion criteria: Patients $<15$ years of age, those having any neurovascular involvement of the upper limb and those having any chemical, thermal and electrical injury were not included in the study.

A detailed history was taken which included:

- Demographic details (Age, Date Of Birth, Gender, hand dominance, site of hand Injury, Socioeconomic Status, Occupation

- Time interval to presentation (Time from injury to presentation)

- Place of Injury.

- Mechanism of injury (machine injury, RTA, assault, fall down, suicidal injuries, others.

- Time interval between accident and the first medical attention received.

\subsection{Initial management}

As initial assessment and management is very important in any trauma patients, we started it as soon as the patient presented to us. Immediately "ABC" of the patients was addressed. Detailed history followed by careful and thorough clinical assessment of the local as well general condition of the patient was done. All Patients were given first aid, analgesics, antibiotic and tetanus prophylaxis cover. If required IV fluid was started. After that the wound was examined if feasible. Fingertips were checked for the presence or absence of vascularity and sensations. Wound was explored in order to identify the extent of damage to the deeper structures. Clean and superficial lacerations were debrided and sutured if necessary. Open wound was thoroughly washed and cleansed with normal saline and povidone iodine solution. The wrist and hand was splinted if a fracture was suspected. These procedures were carried out in the sterile and aseptic environment of the emergency OT. Blood transfusion was carried out if the need rose. This was followed by the radiological evaluation of the injured part. The patient was then taken to the operative theatre for any operative intervention if needed, admitted if required or discharged and called for routine follow up.

\subsection{Statistical analysis}

All data obtained in the study were recorded in MS Excel and analyzed using the Statistical Package for Social Sciences (SPSS) for Windows, Version 16. Numerical variables were given as mean and standard deviation (SD).P values below 0.05 were considered statistically significant.

\section{Results}

Hand injuries are among the most frequent injuries worldwide, constituting between $6.65 \%$ to $28.6 \%$ of all injuries and $28 \%$ of injuries to the musculoskeletal system ${ }^{[3]}$. These occur at workplace, home and in road traffic accidents. Based on the personal data in our series, $88 \%$ were male patients (Fig-1). 36\% of the patients were in the age group of 25 - 35 years followed by $23 \%$ in 15-25 years age group (Fig2). Machine injuries were the main culprits at $52.5 \%$ followed by RTA and assault at $25 \%$ and $13.5 \%$ respectively (Fig-3). Isolated Index finger (12.5\%) was the most commonly injured site followed by thumb (10.5) and middle finger (8.5). Multiple fingers were involved in 97 cases i.e. in $48.5 \%$ cases (Fig-5).

Dominant hand was affected in 127 patients $(63.5 \%)$ (Table2 ). Crush injuries of the hand were found in $41 \%$ of the cases.

\section{Gender distribution}

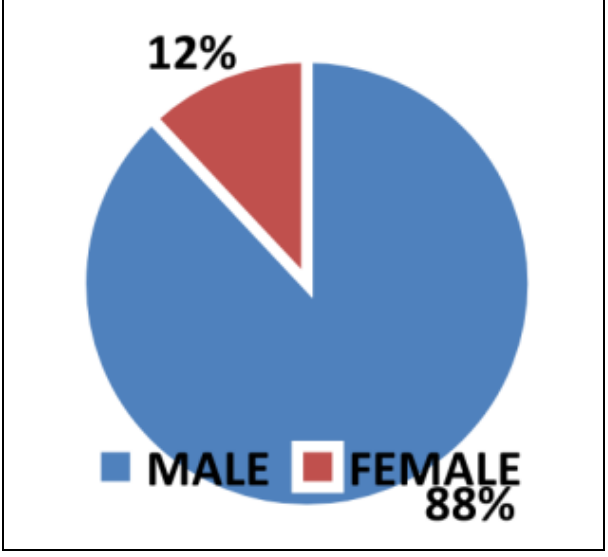

Fig 1: Gender distribution of Hand injuries

Males (88\%) are affected more as compared to females. This contrast in the distribution may be due to the fact that more male population is employed in industrial sector making them more susceptible to hand injuries.

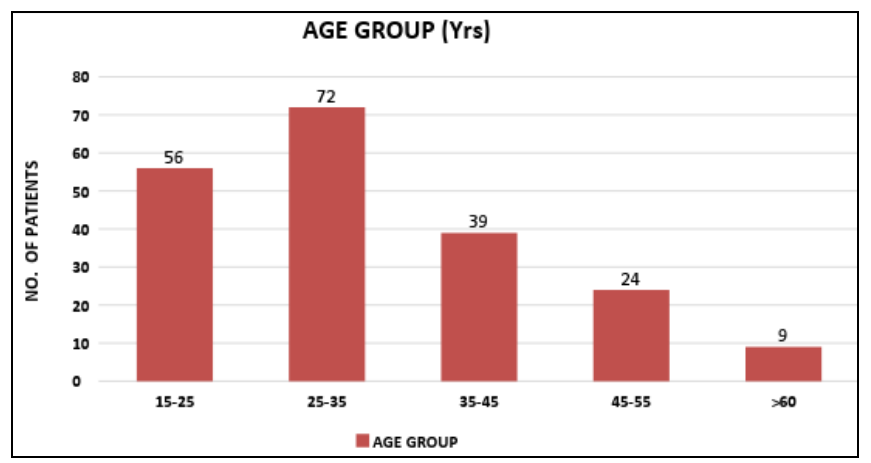

Fig 2: Age Group

138 out of the 200 patients were in the age group of 15-35 years. This could be due to the fact that young people who operate machines are at a higher risk to machine injuries due to their lack of experience.

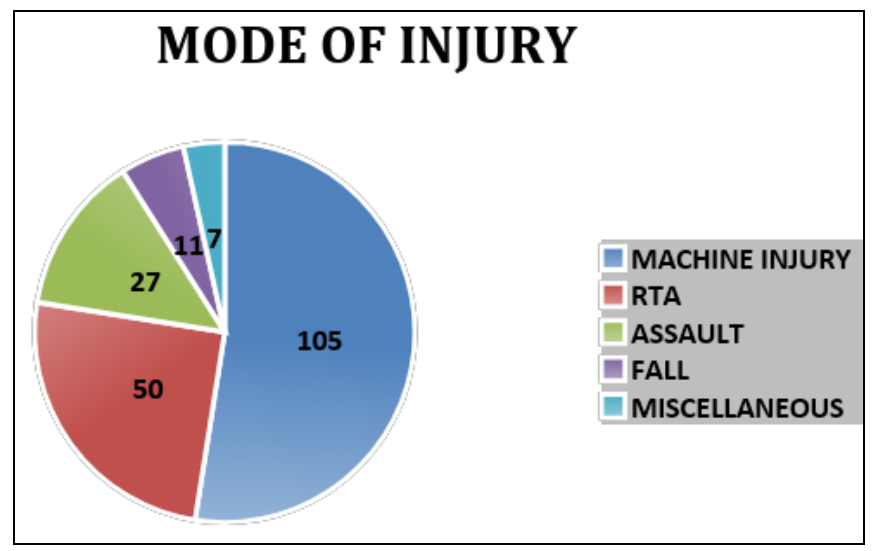

Fig 3: Various Modes of Injury

In our study we found out that machine injuries are major contributors to hand injuries followed by RTA and Assault. 
This could be possible because of the presence of low socioeconomic area surrounding where majority are blue collar workers.

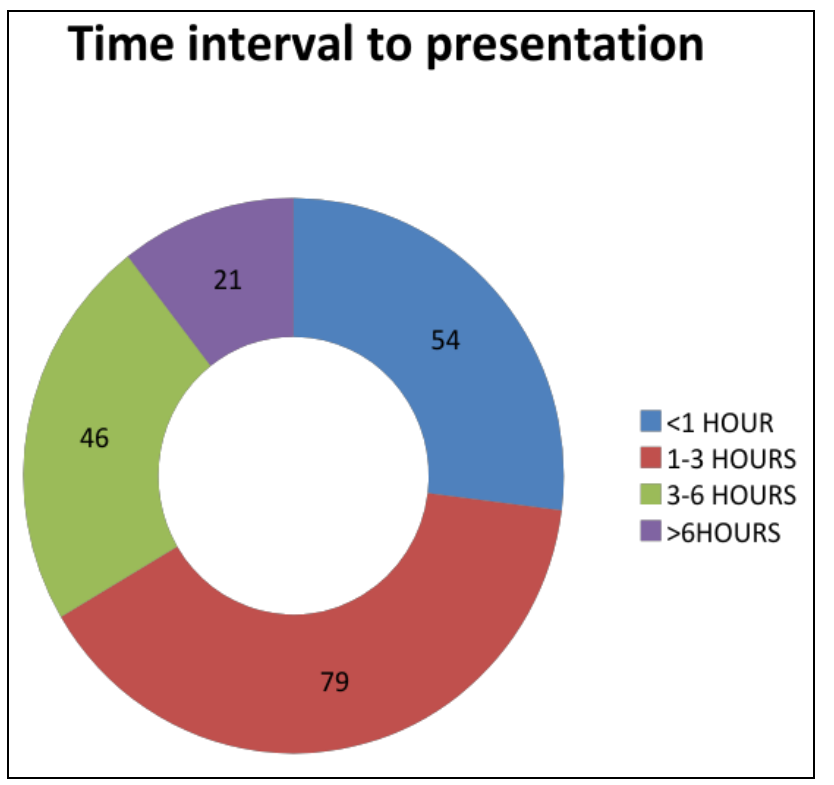

Fig 4: Time interval to presentation

Majority of the patients presented within 3 hours of injury. This is due to excellent 108 emergency services which cater to our institute.

Table 1: Dominant Hand

\begin{tabular}{|c|c|c|}
\hline Sr. No & Dominance & No. of patients \\
\hline 1 & Right & $\mathbf{1 2 3}$ \\
\hline 2 & Left & $\mathbf{7 7}$ \\
\hline
\end{tabular}

Table 2: Injury to Dominant Hand

\begin{tabular}{|c|c|c|}
\hline Sr. No. & Hand & No. of patients \\
\hline 1 & Dominant & 127 \\
\hline 2 & Non dominant & 73 \\
\hline
\end{tabular}

Table 3: Digits Involved

\begin{tabular}{|c|c|c|}
\hline Sr No. & Digit & No. of patients \\
\hline 1 & Thumb & 21 \\
\hline 2 & Index & 28 \\
\hline 3 & Mid & 17 \\
\hline 4 & Ring & 07 \\
\hline 5 & Little & 03 \\
\hline 6 & Multiple & 97 \\
\hline 7 & No digits involved & 27 \\
\hline \multicolumn{2}{|c|}{ Total } & 200 \\
\hline
\end{tabular}

As shown in table-2 multiple digits are injured in more no. of patients.

Table 4: Injury Type

\begin{tabular}{|c|c|c|}
\hline Sr. No. & Injury Type & No. of Patients \\
\hline 1 & Laceration, cut, abrasion & 43 \\
\hline 2 & Contusion & 27 \\
\hline 3 & Fracture and dislocation & 72 \\
\hline 4 & Crush injury & 30 \\
\hline 5 & Amputation & 28 \\
\hline & Total & 200 \\
\hline
\end{tabular}

Table 5: management required

\begin{tabular}{|c|l|c|}
\hline & \multicolumn{1}{|c|}{ Management option } & No. of Patients \\
\hline 1 & Conservative & 71 \\
\hline 2 & Operative & 27 \\
\hline & a) Amputation and closure & 102 \\
\hline & b) Fracture fixation & 76 \\
\hline & $\begin{array}{l}\text { c) Plastic surgical intervention } \\
\text { (Skin Flaps, grafts, tendon repair) }\end{array}$ & 200 \\
\hline & \multicolumn{2}{|c}{ Total } \\
\hline
\end{tabular}

X-ray images

Case 1: 28 yr old male patient history of RTA.
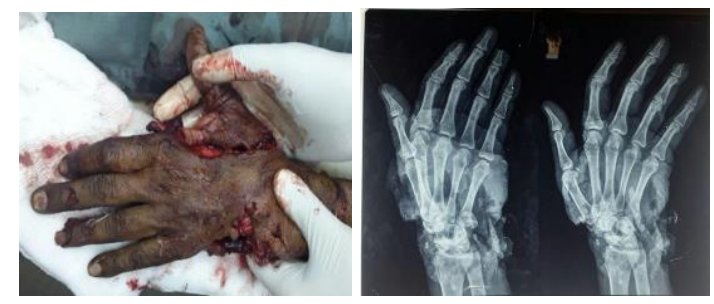

Case 2: 19 yr old male patient h/o machine injury.
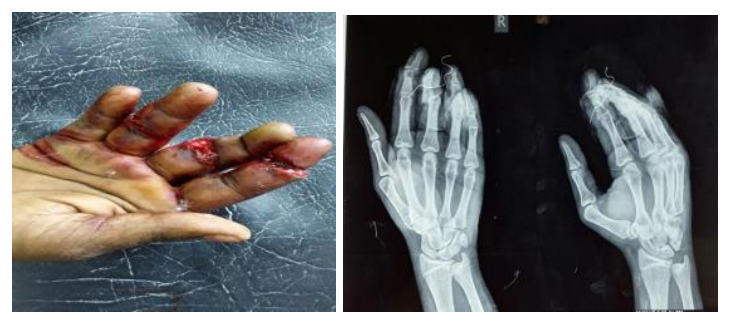

Case 3: 23 y/o male with handcrush from sugarcane juicer machine
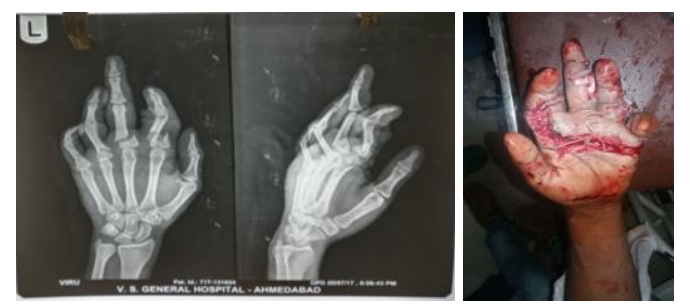

Case 4: 10 year old boy history of beaten by opposite party with sword
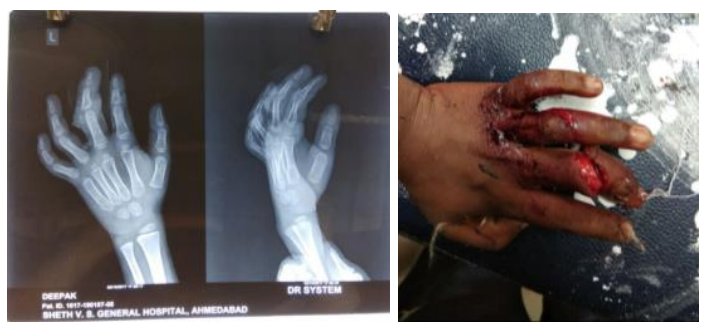

Case 5: 35 y/o male c crush by a industrial newspaper printer
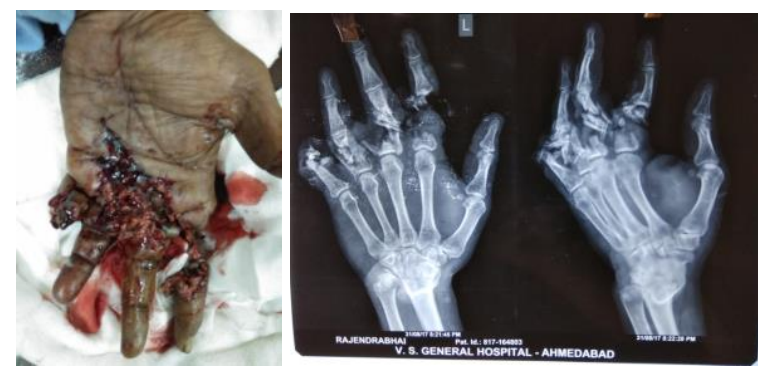

Discussion 
The following results were obtained from the study.

\subsection{Gender}

Males are more commonly affected as compared to females [Fig-1].

\subsection{Age}

People in the age group of $15-25$ years are at a higher risk $(59 \%)$ [Fig-2].

According to other studies mean age of the patients was 27.41 years ${ }^{[6]}, 37.2$ years ${ }^{[14]}, 26.9$ years ${ }^{[15]}$ as compared to 33.01 years in our study.

\subsection{Mode of Injuries}

Machine injuries are the major contributors (52.5\%) followed by Road Traffic Accidents (25\%) [Fig-3]. Acc. to Murtaza et al work place injuries occurred in $74 \%$ of the patients and $16 \%$ of the patients had a road traffic accident; whereas in our study machine injury (workplace injury) accounted for $52.5 \%$ injuries and $25 \%$ patients had a road traffic accident.

\subsection{Site involved}

Acc to Rohini et al. index finger was most commonly injured single finger $(17.5 \%)$ and $32 \%$ patients suffered from multiple finger injuries. ${ }^{[2]}$ In our study only $14 \%$ of the patients suffered from isolated index finger injuries and $48.5 \%$ of the patients had multiple fingers involved.

\subsection{Hand dominance}

In our study $63.5 \%$ (127) of the patients the dominant hand was affected [Table-2]. Acc. to the study done by Hill et al, Right and left hands were affected with similar frequency i.e $51.8 \%$ and $45.4 \%$ respectively. ${ }^{[12]}$ According to Murtaza et al. $39 \%$ of the patients suffered from injuries to right hand whereas $36 \%$ suffered left hand injuries and $11 \%$ of the patients suffered injuries to both hands. ${ }^{[6]}$ in our study we found out that right hand was injured in $61.5 \%$ patients and left hand was injures in $38.5 \%$.

\subsection{Operative intervention}

Our study shown that $35.5 \%$ of the patients were managed conservatively whereas rest $64.5 \%$ patients needed operative intervention. Out of the 129 patients that needed operative intervention; $27(20.93 \%)$ required amputation whereas rest 102(79.07) required some orthopedic intervention.

\subsection{Time of Presentation}

Acc to Hill et al half of the patients reported within 2 hours of injury ${ }^{[12]}$; whereas in our study we found out that 54 patients $(27 \%)$ presented within the $1^{\text {st }}$ hour of injury and 21 patients $(10.5 \%)$ presented after 6 hours of injury. The rest 125 patients $(62.5 \%)$ presented between 1-6 hours of injury.

Young males in the age group of 15-35 years who are required to operate complex machinery are at higher risk to be involved in any form of accidents. Also the dominant hand is affected more, making it more troublesome for the patient to recuperate from the injury. This in turn leads to a rise in physical, mental and financial stress on the patient. Appropriate training should be imparted to them by experienced workers, so that they can be vigilant enough to prevent any mishaps. Also, necessary supervision of these workers needs to be carried out so that such accidents can be reduced. The employers should introduce various schemes such as better working hours, regular breaks etc. to increase the workers' efficiency which will in turn decrease the number of machine injuries. Proper and regular maintenance of the machinery along with safety measures is also of utmost importance. Road Traffic Accidents are also another major contributors to injuries to the hand. They often result due to reckless driving, driving under influence, or due to machine failure. All of the above causes are avoidable. More emphasis should be made to obey the traffic rules and use of protective gear while driving. Even then if any such accident does happen it is imperative that the injured receive quick first aid and urgent medical help at appropriate center so that patients' prognosis can be improved and disability can be reduced.

\section{Conclusion}

Hand injuries are very common in present time. Any injury to the hand has the potential to produce significant and permanent impairment to hand functions and that in turn can cause mental and financial burden. The effects are so profound and long lasting that serious thinking needs to be done for preventive strategies and disability reduction. It would take effort from all; the employers, the employees; the emergency medical staff in order to prevent and rehabilitate the patient suffering from such gruesome injuries.

Take home message: Be careful while working with complex machinery and obey the traffic rules at all times and quickly seek medical aid if any such mishap occurs so that the best possible treatment can be provided to the patient.

\section{Acknowledgements}

We would like to sincerely thank our teachers our colleagues and our department head for their full support in helping us out in this submission.

Funding: This research received no specific grant from any funding agency in the public, commercial, or not-for-profit sectors.

\section{References}

1. Otto C. ABC of Emergency Radiology. Oxford, UK: Blackwell Publishing Ltd, 2007.

2. Rohini Prasad, Arivind Bhamidi, Arunkumar Rajeswaran, Subramaniam Muthukumar, Porkodi Kothandaraman, Meenatchi Sivaraj, Epidemiology and Sequelae of Workplace Hand Injuries at a Tertiary Trauma CareCentre, Department of Plastic, Reconstructive and Hand Surgery, Parvathy Hospital, Chennai, India, Surgical Science 5, 29 March. 2014; 150158

3. National Burden of Disease and Cost Effectiveness Study Final Report on Burden of Disease (Book in Turkish). RSHMB, Ankara, Turkey, December, 2004.

4. Rishabh Gupta, Shavi Mahajan, Deepika Dewan, Rajat Gupta. Pattern of hand injuries reported in a tertiary care setting of North India,Int J Res Med Sci. 2017; 5(3):880884

5. Mustafa Serinken, Ozgur Karcioglu And Serkan Sener, Occupational Hand Injuries Treated At A Tertiary Care Facility In Western Turkey, Department Of Emergency Medicine, Acibadem Bursa Hospital, Bursa, Turkey, 2008.

6. Murtuza N. Ghiya, Shakuntala Murty, Naren Shetty, and Rodney D'Cunha,A descriptive study of hand injuries presenting to the adult emergency department of a tertiary care center in urban India. 2014, 19-25, doi 10.4103/0974-2700.199519 
7. Ghulam Mustafa KaimKhani, Syed Mujahid Humail, Kamran Hafeez, Naveed Ahmed Pattern of bony injuries among civilian gunshot victims at tertiary care hospital in Karachi, Pakistan, Chinese Journal of Traumatology. 2015; 18(3):161 163, doi:10.1016/j.cjtee.2014.10.003

8. Larsen CF, Mulder S, Johansen AMT, Stam C. The Epidemiology of Hand Injuries in the Netherlands and Denmark. European Journal of Epidemiology. 2004; 19:323-327.

9. Aksan AD, Ada RDS, Kayalar M, AKSU F. Bal E. Epidemiology of Injuries Treated at Hand \& Microsurgery Hospital. Acta Orthopaedica Traumatologica Turcica. 2010; 44:352-360.

10. Garg R, Chung JPY, Fung BKK, Ip WY. Epidemiology of Occupational Hand Injuries in Hong Kong. Hong Kong Medical Journal. 2012; 18:131-136.

11. Ihekire O, Salawu SA, Opadele T. International Surgery: Causes of Hand Injuries in a Developing Country. Canadian Journal of Surgery. 2010; 53:161-166.

12. Hill C, Riaz M, Mozzam A, Brennen, A Regional Audit of Hand and Wrist Injuries. A Study of 4873 Injuries. Journal of Hand Surgery. 1998; 23:169-200. http://dx.doi.org/10.1016/S0266-7681 (98)80174-5.

13. Tayal VS, Antoniazzi J, Pariyadath M, Norton HJ. Prospective use of ultrasound imaging to detect bony hand injuries in adults. J Ultrasound Med. 2007; 26:11438 .

14. Sorock GS, Lombardi DA, Hauser R, Eisen EA, Herrick RF, Mittleman MAA. Case-crossover study of transient risk factors for occupational acute hand injury. 2004; 61(4):305-11.

15. Ogemdi Ihekire, Siddiq AI. Salawu, Temilolu Opadele, Causes of hand injuries in a developing country, Can J Surg. 2010; 53(3):161-166. 